\title{
A DEAF BODY: OPPRESSION AND RESISTANCE IN A BRAZILIAN PERSPECTIVE
}

\author{
Lygia $P$. Neves \\ Curso de Mestrado Profissional em Diversão e Inclusão, IB, Universidade Federal Fluminense, Niterói, \\ Brazil. \\ Patrícia L. F. Rezende \\ Instituto Nacional de Educação de Surdos, Rio de Janeiro, Brazil.

\section{Leonardo A. Silva} \\ Programa de Pós -graduação em Ciências e Biotecnologia, IB, Universidade Federal Fluminense, Niterói, \\ Brazil.

\section{Luciana P. Silva} \\ Programa de Pós -graduação em Ciências e Biotecnologia, IB, Universidade Federal Fluminense, Niterói, \\ Brazil.

\section{Helena C. Castro} \\ Programa de Pós -graduação em Ciências e Biotecnologia, IB, Universidade Federal Fluminense, Niterói, \\ Brazil.
}

\begin{abstract}
Deafness, legal rights, language, teaching and learning are topics strictly related to deaf life and wellbeing. This article aims to discuss the history of deafness and some teaching proposals using Brazil and a Brazilian Institute of Deaf Education in a study case. On that purpose we analyzed didactic and scientific materials and their influence on Brazilian deaf education. Thus, we focused on the deaf speech also approaching pathology and epistemology perspectives present in the narratives of the institute curriculum, questioning these representations. Historical aspects in the educational, pathological and epistemological approaches in Brazil are also reported including different language teaching perspectives including bimodalist, total communication and bilingualism. Our study observed the importance of deaf political movement and their struggle to guarantee the right for a good and long-awaited dreamed bilingual education.
\end{abstract}

Keywords: deaf, Epistemological, pathological, speech, Deaf movement. 


\section{INTRODUCTION}

The deaf culture, language, politics, and educational approaches have been recently discussed by some authors. However, investigations about the stereotyped vision regarding deaf subjects may bring together theoretical and political components against the discriminatory nature involving the curricular proposals for educating deaf people.

The analysis of deafness history has been explained, fundamentally by doctors, linguists, psychologists and who develops until today paradigms to deaf education. According to Carlos Skliar deafness is:

A visual experience, a multiple and multifaceted identity, which constitutes a politically recognized difference and located, most of the times, within the discourse of disability. (SKLIAR, 1999, p.11)

According to Skliar, deafness has not only defined the role of language but also provided feasible conditions for the construction of the deaf identity, culture and linguistics. These relevant conceptions such as identity, difference and subjectivity are inserted within deaf knowledge. In this way, the discourses on deafness are part of the discussion of individuals with disabilities that have been constituted and narrated by different interpretations.

Deaf Studies has involved questions that seek to establish a field of cultural knowledge that narrates the deaf culture in its production of meanings. This knowledge field also represents a view with poststructuralist inspiration, which leads us to understand that the deaf are a social, linguistic and cultural subject. Deaf studies are referred to in the presence of theories such as Cultural Studies, Postcolonialism, Post Structuralism, Postmodernism that have promoted a significant and fundamental rupture in history, life, political strategies and struggles of the deaf. Deaf and Cultural Studies opens a new way of thinking that drives differences and politics.

The cultural theory motivates studies not only on culture but also involving identity, language, power positions, and pedagogy. This approach about deaf and cultural studies is based on the post structuralist theory bringing deafness and deviant subjectivity conceptions, contrasting it (Foucault, 2004).

In order to understand the different linguistic contexts that represent the deaf as subjects - deficient, or subject-linguistic - it was necessary to adopt the commitment of deaf subjects to the education policy movement and its deaf community for the struggle and emerge of a bilingual education. Thus, the main question for this research is to discuss in a critical point of viewing the reason for the linguistic oppression of the deaf educated by a governmental educational system using a Brazilian Institute of Education of Deaf and their educational parameters as a study case. As a consequence of this work, we raise questions such as What does the deaf represent to society? What do the INES book pictures represent? The meaning of the deaf? What the production of the INES pedagogical and scientific materials represents to the language development of the deaf student?

\section{METHODOLOGY}

We performed a qualitative analysis by evaluating didactic materials used for teaching deaf such as: a) the book "INES And The Education Of Deaf In Brazil" by Solange Rocha, b) pedagogical and scientific materials produced by National Institute of Education of the Deaf (INES) including the DVD "cá entre nós", "joão e maria", and about coclear implant. We explored this analysis together with Skliar and Foucault theories and others such as those in which the linguistic cradle of deaf students and the deaf community in the analytic perspectives approximates the look of difference of the teaching with the curriculum that proposes for the construction of the deaf linguistic subject. 


\section{RESULTS}

\section{DEAF SUBJECT: THE HISTORICAL/PATHOLOGICAL VIEWS}

It is worthy to notice that obviously deaf community is formed by epistemological subjects considering their language and culture, which also is represented by the deaf politicized subjects. On that perspective herein we used the term body that is the simplest definition that all have learned in science and biology at school. Therefore, what differs the body of a deaf person from the hearing people body? how to analyze the deaf body? Is this body unruly? a cursed body? a deformed, a repressed or a sentenced body?

After all, the deaf body illustrates and nurtures its own historical conception that becomes relevant when in antiquity, the Greeks saw the deaf as animals as according to their perspective, thoughts were shown through speech. At that time, without hearing, deaf was out of the teaching system and without that, they did not acquire knowledge. The Romans deprived the deaf of legal rights such as they neither could get marry, nor inherit the assets of the family. According to the main religion of that time, the Catholicism, the deaf was considered a human being without salvation that would not go to the God kingdom after death.

Until recently, the condition of the deaf subject was the most miserable of all, as society treated them as imbeciles, abnormal and incompetent people. A historical moment was the Milan Congress of 1880, when this meeting involving educators in various countries discussed about deaf education and put it into practice. In the very moment that sign language was enacted, the aim was to consider the oral language and the oral method in deaf education as the best option. Despite new concepts emerged to define deafness and its communication, deaf people entered to the training list to be someone that should use an exclusive oral language - in Brazil the Portuguese, which is the majority language - that was applied and presented using medical and therapeutic formats. Apparently the main message was to label the deaf as a handicap person, without understand them as part of a linguistic minority that need to be respected and listened. This is in accord with Skliar statements:

The other deficient was invented in terms of an evil alterity, a denial of his body, a robotization of his mind. But let's not talk again about the malice of his body, but about this evil invention: the construction of normality (SKLIAR, 1999, p.168).

Skliar presents his theory about the listeners' representation of deaf and deafness, by using the oralism as an institutionalized form that spread the perception of the deaf-deficient, which legitimates the therapeutic practice. Skliar discussed about the dominant ideology regarding the oral majority language and the risk factor of social exclusion by using the sign language and be part of linguistic minority, suffering linguistic oppression.

\section{THE DEAF SUBJECT IN THE EPISTEMOLOGICAL VIEW}

According to Plato, epistemology is the philosophy of life that describes the set of transformations of the subjectivity of the natural and innate world. Epistemology involves science and knowledge as the human reaches the logic of thoughts. Sign language is like any other language, involving phonological, morphological, syntactic, semantic and pragmatic aspects. Thus, it is a language that can capture and express the visual experiences characteristic of deaf communities, such as reported by Wrigley's (1996):

Generations of deaf signposts have demonstrated the existence of a language rich enough to be expressed in different forms, including through poetry and history. (WRIGLEY, 1996, p.17)

Visual experience means the use of sight - in the case of the deaf in total replacement of hearing - as a means of communication. Therefore, when it is asked What is it to be deaf? the answer is: Being deaf is not a matter of being disabled, but a linguist of a visual experience. 
Deaf identity is directly associated with the legitimization of sign language. In the characterization of Brazilian deaf identities, studies such as those of Perlin and Skliar considered the following categories of deaf identities, marking them by heterogeneity:

Deaf identities are those present in the group of deaf people who make use of the visual experience itself. The deaf adult, in meetings with other deaf people, is led to act intensely and, in contact with other deaf people, will build their identity strongly centered on being deaf and on deaf political identity. (SKLIAR and LUNARDI, 2000, p.20)

The deaf culture arises from this visual experience, which is represented not only by the sign language, but also by the different way of being, expressing, and acknowledging the world, and also on understanding and producing arts, scientific and academic knowledge and data. The current pedagogical literature emphasizes the need of deaf teaching strategies using: a) visual teaching protocols, b) sign language and c) deaf teachers. It calls for other considerations such as different educational methods, language narratives and even health. Due to the "biological" differences and sign language authenticity, the deaf is simply recognized as an epistemological subject. Can we better think about what is deaf after all? a representation for society in an epistemological or pathological perspective?

\section{THE ORALISTIC EDUCATIONAL APPROACH}

Throughout history deaf people have been and still are treated as disabled people that do not have the capacity to carry out many activities, including being deprived of having the minimum rights of respected citizens for not communicating orally and not being part of the culture of the listening society (GOLDFELD, 1997).

In 1952 a didactic approach was implemented using phonemes and a pure oral method. This implementation suggested that deafness had a cure and the definition/name deaf-mute no longer made sense as deaf may speak and therefore live within the hearing people society being able to directly communicate with them. The methodology was the oralism, which grounded and encouraged speech. At that time, he opted for pedagogical models that express the inheritance of an institution, direct or indirect, left for the current educators - a clinical model, oralist-assistencialist in the education of the deaf.

The central idea of oralism is that the "auditory deficient" suffers from a chronic pathology, translated by injury to the auditory canal and / or cortical area, which, in order to obstruct the "normal acquisition of language", requires clinical interventions by specialists, Only to "restore speech" to this type of "sick person" (SOUZA, 1998, p.4).

According to some reports on INES education, the method of oralization was the main base in which the deaf student was taught by using oral methodology. At the beginning of the history of deaf education, the deaf people were considered intellectually 'inferior' and subaltern, for their lack of speech and hearing.

Research and experiments emerged from different methodologies and adapted forms of teaching, such as oralism. Due to technological developments that facilitated the practice of oralization by the deaf subject, oralism gained strength from the second half of the nineteenth century. Oralism, or oralist philosophy, uses the integration of the deaf child into the listening community, giving him or her the ability to develop oral language (in the case of Brazil, Portuguese). Oralism perceives deafness as a deficiency that must be minimized through auditory stimulation. (GOLDFED, 1997, pp. 30 and 31).

This system of education for the deaf, under the traditional theory, is shaped in the form of a pedagogy mainly composed by listening principles. The culture of the listener has always been present in the deaf teaching and according to Foucault in The Abnormal (2001) they described the abnormality figures in which the person is to correct. So deaf are people to be corrected, to be transformed from handicapped to an useful person. 
The listeners pedagogy included the application of innumerable oralist methods, searching for teaching strategies that could turn into reality the desire to see the deaf subjects talking and listening. This led to the Brazilian government to spend an enormous sum of money for the acquisition of equipments to potentiate the auditory sense of deaf people. The formation of teachers that often played the role of speech therapists had the main educational proposal directed only to the rehabilitation of speech to the deaf subjects. Foucault in "In Watching and Punishing" (2010) states that the norms and values of modernity over normal, disciplined, and beautiful bodies and minds produce the normalized society.

Focault quotes the view of prejudice and stigma, which could be related to deaf subalternization. Are there stereotypical positions regarding deafness and why using these stereotyped concepts? Thus, it is needed to rethink carefully why a representation of the deaf as deficient alterity, wild, or disorderly and abnormality still is emphasized. Should be asked if hearing people do not respectfully pay attention when deaf people say: (...) Deaf are hearing people with defective ears. (WRIGLEY, 1996, p. 71). The main questions when you are deaf are Why do we have to adapt? Where is my linguistic space? what are my rights as a deaf person? Deaf is seen as a special need person classified within the abnormality.

In education, deafness as a disability marks a determining body, and its learning is invented through the reference listener, corrective pedagogies, normalization and specialists who have founded a field of knowledge capable of "giving" to all those who do not fit In an idealized profile of normality. (LOPES, 2007, p.8)

Deaf people still live under the domination of a disease in need of a cure and sometimes with stigmatization as well. It is possible to understand the dimension of the stigmatization process imposed on bodies that did not fit in the current ideology of perfection, since "society establishes the means of categorizing people and the total of attributes considered as common and natural for the members of each one ". (GOFFMAN, $1975, p .5)$.

\section{EDUCATIONAL STRATEGIES FOR TEACHING DEAF STUDENTS: BIMODAL, TOTAL COMMUNICATION AND BILINGUALISM}

Bimodalism aims to facilitate the development of speech and sign language, by teaching the sign language following the grammatical structure of the oral language. Góes (1996) informs that these approaches - the oralist and bimodalist - synthesize two ideologies that underlie the education of the deaf: the first privileges only one language, in contrast to the second, which establishes an effective space for sign language as well.

Bimodalism is characterized by the simultaneous use of signs and speech, but this is criticized by some authors such as Sacks:

There is an understanding that something must be done (before oralism): but what? Typically using the signs and the speech, allow the deaf to become effective in both. There are other compromise suggestions, containing a profound confusion: an intermediate language between English and Signal (or Signed English). This confusion has long been traced back to I 'Epée's "Methodical Signs," which were an attempt at intermediation between the French and the signal. But it is not possible to transliterate a language spoken in Signal word by word, or phrase by phrase. The structures are essentially different. It is often imagined, vaguely, that the sign language is English or French: it is nothing of the sort; itself, Sign. Therefore, the "Signed English", now favored as a compromise, is unnecessary as it does not need any intermediate pseudolanguage. And yet the deaf are forced to learn the signs not for ideas and actions they want to express, but for phonetic sounds in English that they cannot hear. (SACKS, 1990, p.47) 
Total Communication is different from Bimodalism and according to Denton apud Freeman, Carbin, Boese (1999):

Total Communication includes the full spectrum of language modes: gestures created by children, sign language, speech, oro-facial reading, handwritten alphabet, reading and writing. Total Communication incorporates the development of any hearing debris for the improvement of speech or reading abilities, through constant use over a long period of time of individual hearing aids and / or high fidelity amplification systems In group (p.171)

These teaching strategies present differences in methodological approach that allowed building politicalpedagogical projects with focus on the listeners produced knowledge world. Differently, Bilingualism is a strategy that uses sign language as the first language for teaching deaf students whereas the oral language Portuguese in case of Brazil - is presented as the second language and in the written modality.

Bilingualism is a teaching proposal that emerged within the deaf schools in the 1970s and had arisen initially from the idea that the deaf need to be instructed in two languages. It is considered as the most adequate proposal for teaching deaf children, since it considers sign language as the first language and from there they move on to teaching the second language (Portuguese) that can be in the written or oral mode. Bilingualism has as basic assumption that the deaf should be bilingual, acquiring the sign language as the native language, which is also considered as their natural language and, as the second language, the official language of their country.

\section{DEAF EDUCATIONAL HISTORY: ANALYSIS OF THE BRAZILIAN INSTITUTION OF EDUCATION OF THE DEAF (INES)}

The analysis of Brazilian history pointed to Huet and his experience in an institution for the deaf in France: the Institute for the Deaf-Mutes in Bourges, France. The Brazilian imperial government Dom Pedro II supported Huet initiative with the creation of a Brazilian educational Institute (INES) that began operating on January 1, 1856, the same date as Huet teaching proposal was published. This proposal contained the disciplines of Portuguese, Arithmetic, Geography, History of Brazil, Bookkeeping, Articulate Language, Christian Doctrine and Reading on the Lips. The ideology of modernization of the 1950s in Brazil and its discussions on education of the deaf, was also inscribed. The institution of education of the deaf (INES) received and still receives students from all regions of Brazil and became a reference abroad for deaf education, professionalization and socialization.

The sign language practiced by the deaf in the Brazilian Institute suffered a strong French influence, due to the Huet nationality. In the early decades of the twentieth century, the Institute also offered vocational training in addition to literary instruction. According to their abilities, the students attended workshops of shoemaking, tailoring, printing, carpentry and plastic arts.

"Many have been busy writing the deaf, starting with deficiency, proposing the correction of speech, oralization. Questions like this do not refer to the issue of difference, subject and power. Flee from them, they, in themselves, reveal the power of hearing over the deaf. This power is labeled by Wrigler (1996) as administrative power over the deaf. (Perlin, 2003, p.52)."

In our work we analyzed the pedagogical game produced by INES of DVD "Cá Entre Nós". According to this material, it facilitates the acquisition of oral and written Portuguese and motivate the Deaf to use oral and written Portuguese in an audience environment. Since the Brazilian Educational Institute claims to use Bilingualism, this emerged questions about the purpose of this material including: This is the proposal of a bilingual approach? Oral and Brazilian Sign language - Libras? This also broadens a discussion about the use of the method of Oral Communication. Probably Bimodalism and not Bilingualism has been used by the Institute. So what is the main incentive of this proposal for the deaf student? Bimodal and oral method? In one of the sentences it is included "How to deal pedagogically, linguistically and socially with the Cochlear Implant in various school contexts". Maybe with no further intention, it may be interpreted as an 
insinuation for a perfect body, enlarged and beautiful, since the implant is the healing of the ear and speech, linguistically, and pedagogically. This also raises the question about the necessity of including the Cochlear Implant in the curricular parameters, and of the teaching methodology or at least the need of clarifying it.

In the last sentence it says: "It tries to avoid the dichotomy of the against or in favor of the subject". However, it is important to discuss this topic in forums and seminars to show the disadvantages of the cochlear implant including surgery process as well as the impossibility of getting important health exams such as Nuclear Magnetic Resonance. Therefore, it is important to avoid this technical assistance that implies the constitution of a normal subject such as pointed out by Capovilla (2000) that reports that the oral method will aid in the development of the deaf subject to interact as a normal product:

In explaining the oralist method in communication with the oral method, the objective was to lead the deaf to speak and develop oral linguistic competence, which would allow him to develop emotionally, socially and cognitively in the most normal way possible, integrating himself as a productive member of the World of listeners. (CAPOVILLA, 2000, p.102)

The Sign Language, in the eyes of some from our society, is still considered as not normal, and does not make sense or fit. This brings back ancient perspectives in which "Deaf people have to pray, to learn to read lips, to listen and to live like all normal beings." Thus, we have to be careful with the didactic material produced by this so-called reference Brazilian Institute of Deaf education.

Despite this material profile, the Brazilian Institute of education of deaf is really important to the country and when the Minister of Education (MEC) tried to close it, Brazilian Deaf revolt!

We experienced this story. Firstly as deaf, representatives of the Brazilian deaf communities and, secondly, as researchers, with an activist spirit. We can not deny our history, intensely linked to the diagnosis of the field of struggles and battles. (CAMPELLO, REZENDE, 2014, 72)

It was a sweat battle, a struggle, and an intense political debate against MEC. The two great leaders in deaf politics and representatives of the community, Campello and Rezende, reported their experience as activists and researchers, with reasoning and emotion, as they know the priority of the ideal education for the deaf community.

In order to have a quality bilingual education, bilingualism with clear L1 and L2 perspectives, the cognitive construction of the deaf subject, including LIBRAS, culture and identity, Campello and Rezende joined and fought against those rules imposed on deaf education represented by the attempt to close INES. This struggle extends a critical and constructivist view on the education of the Deaf that is yet to be discussed, and settled.

\section{DEAFNESS AND THE BRAZILIAN POLITICAL PERSPECTIVES}

The Brazilian deaf struggle movement is a resistance to the oppression culture in the national sociopolitical scene. Despite its significance, little visibility has been given by the listener culture that unfortunately still do not respect the deaf culture despite its undeniable importance in the present society.

Among the many claims of this movement, it is evident the bilingual proposal of education for the deaf that seeks not only the best form of education for their community but also for the maintenance / affirmation of the deaf culture against those who only preach Pathologization and Transformation of deafness.

Flaviane Reis (2006, p.39) presents the main aspects of deaf culture and community in cultural studies.

"- Be Deaf: subjectivity takes its stance with identity, culture, otherness, accepting oneself as deaf, the politics of striving for difference; 
- Deaf people: the group from which deaf individuals participate in political struggles, a place of our culture, language and pedagogy, a place where deaf people participate in sports in deaf championships, parties, deaf marriages, visual theater, and various events ;

- Politics with its flags of struggle: a) for recognized cultural linguistic rights; $B$ ) in the education of the deaf and its political / educational aspects ".

According to Reis, deaf community has the right of a linguistic choice (eg. inclusive or bilingual education). Deaf people struggle for having more visibility in our society at all levels, and even the agreement to deaf choose about being DIFFERENT, and not DEFICIENT.

Historically deaf politics is initiated thanks to FENEIS, which is a philanthropic, non-profit organization with a sociocultural, welfare and educational purpose. It aims to defend and fight for the rights of the Brazilian Deaf Community. It is affiliated to the World Federation of the Deaf and its activities have been recognized as of Federal Public Utility.

The deaf movement and the deaf community in Brasília fighting against the closure of INES aimed to draw the attention of political authorities, the media and society to the needs of deaf people and the deaf culture. Although Brazilian legislation guarantees deaf people various rights, many of these are still not properly respected in the country.

The bilingual education of the deaf in Brazil is supported by the Law and is recommended by the National Ministry of Education (MEC) as a valid and effective proposal for teaching the two languages legally recognized by the country. LIBRAS and Portuguese is necessary for social and effective inclusion of these subjects in our society. Decree No. 5,626 of December 22, 2005, which regulates Law 10.436 / 2002, in its chapter VI, Article 22 establishes that, for school inclusion,

"I - bilingual schools and bilingual education classes, open to deaf students and listeners, with bilingual teachers, in early childhood and early childhood education;

II - bilingual schools or regular schools of the regular educational network, open to deaf students and listeners, for the final years of elementary education, secondary education or professional education, with teachers from different areas of knowledge, aware of the linguistic singularity of deaf students, As well as the presence of translators and interpreters of Libras - Portuguese."

Also in article 22, paragraph 1, this Decree describes as a bilingual school or class of education "those in which Libras and the written modality of the Portuguese are the language of instruction used in the development of the whole educational process." The recognition by Brazilian Law No. 10.436 / 2002, LIBRAS as the official language, paved the way for bilingual education for the deaf and acceptance of the existence of a "deaf culture".

Bilingualism has been following in the educational milieu of the deaf community and experts in the field as the last word in education. The doors begin to open to this new perspective, but for many people, as if it were a "lifeline" and not a really conscious option (FERNANDES, 2008)

\section{DEAFNESS FROM A DEAF PERSPECTIVE}

This article has two deaf authors (first and second authors) that want and need to express their own perspectives when they see this kind of questions described below:

a) Why Accessibility? Deaf people are able to live with the normal (listeners) and sign language is not necessary! 
b) "The Deaf has to be implanted!!! That will be the way of happiness, and an impact of the current technology!

c) "Because using sign language is ugly and imprecise. There are no grammatical rules, and this gives the impression of Deaf being an Unhappy Mute! For what signs then!? Deaf people have to learn to speak as an obligation for their own good, well-being and success professional future because otherwise they will be social failures! A national shame, the Deaf Mute Unhappy cleaning floor, selling jellybeans and supermarket packers.

d) The main rule is for the Deaf to be a Happy is to be a Talking Deaf because that's how they'll get to have a real profession! You will be a great engineer, lawyer, teacher and executive! Yes, it is the best outlet for the well-being of all Deaf Brazilians:

e) Lets give them The Cochlear Implant, and Adapted Speech! Since Sign Language (LIBRAS) is not worth anything!!! So let's straighten them out and be "normal"?!

How answering to those who think that Deaf has no language, and therefore no identity and culture! The authors answer: We are banished, and demoralized just like Indian people and vice versa! Also, like the woman. We are used, beaten and smeared. Considered demons raping in the night. Like a stinking body, and a rotten object. We are the most repugnant pests. Being Deaf is like a sick body, clothed with wounds. Embedded and ebbing pus! We are subjects that rest in the dirt. Incarnate in its leather, and body sifted by the bites, putrid by the stones that melts, and atrophied by the glue that inhales. Deaf so hardy by the violence that surrounds him. The gross violence that is training! Innocence has never visited him since, childhood has been stolen through public investments in the cochlear implant that rules even supported by educational institutions despite our own health risk.

\section{FINAL CONSIDERATIONS}

The analysis of the history and some educational materials from an important Brazilian deaf educational Institute allowed to show the importance of investing in bilingual education in L1 and L2, including in the main Institute of Education of Deaf in Brazil. INES is considered as a reference to be follow and therefore should be very careful on its approach on teaching deaf people.

Deaf oppression involving the non-recognition of its culture and right of using sign language as first language (L1) and the impact of these pathological stereotypes due to the lack of hearing and speech, where deaf is considered only as a deficient individual who does not listen and talk should also be banished from society.

\section{REFERENCES}

1. BRAZIL. Decree n. 6,949, dated August 25, 2009. It promulgates the International Convention on the Rights of Persons with Disabilities and its Optional Protocol, signed in New York on March 30, 2007. Federal Legislation. Official Journal of the Union, Brasília, DF, August 26. 2009. Accessed on 02/02/2016.

2. BRAZIL. Law No. 10,436, of April 24, 2002. Provides on the Brazilian Language of Signals LIBRAS and makes other provisions. Available at: http://www.planalto.gov.br. Accessed on: 08 Mar. 2010.

3. CAMPELLO, A. R.; REZENDE, P. L. F. In defense of the bilingual school for the deaf: the history of struggles of the Brazilian deaf movement. Educar em Revista, Curitiba, Brazil, Special Edition n. 2/2014, p. 71-92. Editora UFPR

4. CAPOVILLA, Fernando C. Educational Philosophies regarding the deaf: from oralism to total communication to bilingualism. Brazilian Journal of Special Education, v.6, nº 1, 2000, p.99-116.

5. [Links] Total communication: introduction, strategies deaf person. $2^{\mathrm{a}}$ ed. Rio de Janeiro: Medical Culture, 1996.

6. FERNANDES, E. (org.) Deafness and Bilingualism.Porto Alegre: EditoraMediação, 2008.

7. FOUCAULT, M. The Birth of the Clinic.Rio de Janeiro: University Forensics. 2011.

8. Foucault, Michel. Watch and Punish. 38 ed. Petrópolis, RJ: Vozes, 2010.

9. Foucault, Michel. The Anormais, 2001. Lil'roria Martins Fome.1 Editora Ltdo

10. Foucault, Michel. Microphysics of power. Publisher Graal, 2009. 
11. FREMAN, Roger D., CARBIN, Crifton F, BOESE, Roberto J. Does not your child listen? A guide for everyone dealing with deaf children. Brasília: MEC / SEESP, 1999.

12. GOFFMAN, E. Stigma: notes on the manipulation of impaired identity. Trad. Márcia E. Stigma: notes on the manipulat

13. GOFFMAN, E. Stigma: notes on the manipulation of impaired identity. Trad. Márcia 